$\begin{array}{r}\text { Phinisi Integration Review } \\ \text { Vol. 1, No.2, Agustus 2018 Hal 208-115 } \\ \text { Website: } \text { http://ojs.unm.ac.id/pir } \\ \text { p-ISSN: 2614-2325 dan e-ISSN: 2614-2317 } \\ \hline\end{array}$

\title{
Muhammadiyah Di Kota Makassar 1985-2015 (Kajian Tentang Pendidikan Dasar Dan Menengah)
}

\author{
Sry Rahayu \\ Pendidikan Sejarah, Program Pascasarjana Universitas Negeri Makassar \\ Email: sryrahayu1373@gmail.com
}

\begin{abstract}
Abstrak. Kajian ini membahas tentang eksistensi Muhammadiyah Kota Makassar 1985-2015. Memahami peran Muhammadiyah Kota Makassar dalam mengelola pendidikan.Menganalisisis pengaruh Muhammadiyah terhadap masyarakat Kota Makassar dalam bidang pendidikan.Jenis penelitian ini adalah penelitian dengan menggunakan pendekatan deskriptif analitis. Teknik penulisan dan pengumpulan data menggunakan metode sejarah dengan empat tahapan yakni heuristik (pengumpulan data), kritik (analisa data), interpretasi (menafsirkan data), historiografi (menuliskan data menjadi suatu peristiwa yang utuh). Hasil penelitian ini menunjukkan, bahwa terbentuknya Muhammadiyah Kota Makassar dipelopori oleh Al-Yamani. Al-Yamani dikenal sebagai seorang pedagang batik dari Surabaya, yang membuka toko di Passar Straat sekarang jalan Nusantara Makassar. Dalam dunia pendidikan, Muhammadiyah telah banyak memberi sumbangsih dengan mendirikan madrasah-madrasah dan pesantren dengan konsep kurikulum pengajaran ilmu pengetahuan Islam dan umum. Lembaga pendidikan yang didirikan oleh Muhammadiyah kemudian dikelola dalam bentuk amal usaha dengan penyelenggaranya dibentuk sebuah majelis dengan nama Majelis Pendidikan Dasar dan Menengah. Dengan hadirnya sekolah-sekolah Muhammadiyah dibidang pendidikan meletakkan dasar Islam, berpedoman Al Qur'an dan Hadits. Dengandasar dan pedoman tersebut akan membentuk manusia muslim yangberakhlak mulia, cakap, percaya pada diri sendiri, dan berguna bagi masyarakat.
\end{abstract}

Kata kunci: Muhammadiyah, Pendidikan, Makassar

Abstract. The study aims at discovering the existence of Muhammadiyah in Makassar in 1985 2015, understanding the role of Muhammadiyah in Makassar in managing the education, and analyzing the influence of Muhammadiyah on the people in Makassar in education field. The study employed descriptive analytic approach by providing specific description on the profile of Muhammadiyah in Makassar, the way Muhammadiyah in managing education, and its influence on the people in Makassar. The techniques of writing and data gathering employed history method conducted in four stages, namely heuristic (data gathering), critique (data analysis), interpretation (data interpretation), historigraphy (writing the data into a whole event). The results of the study reveal that the establishment of Muhammadiyah in Makassar was pioneered by Al-Yamani. Al-Yamani was well known as a Batik seller from Surabaya, who opened the store in Straat market, now as Nusantara Street in Makassar. In the field of education, Muhammadiyah had given numerous contribution by building many madrasah and pesantren (Islamic schools) with the concept of teaching of Islamic and general science curriculum. The educational institution established by Muhammadiyah was managed in the form of a business charity with the organizer formed an assembly with the name of Assembly of Primary and Secondary Education with the existence of schools of Muhammadiyah with the foundation of Islam based on Al Qur'an and Hadith. Based on the aforementioned foundation, it will form a Muslim with noble characters, competen, confident, and useful for the people.

Keywords: Muhammadiyah, Education, Makassar 


\section{PENDAHULUAN}

Muhammadiyah merupakan gerakan Islam dengan tujuan pembaharu yang bisa berarti pemurnian, maksudnya adalah pengembalian ajaran Islam yang sesungguhnya berdasar pada Al-Quran dan As-Sunnah.Ajaran Islam yang telah bercampur dengan kepercayan nenek moyang berupa kepercayaan animisme dan dinamisme telah melahirkan pengalamanpengalaman agama yang menyimpang dari ajaran Islam.Hal inilah yang menjadi sasaran utama Muhammadiyah di Makassar untuk menghapus segala kebiasaan-kebiasaan yang dianut sejak dulu oleh masyarakatnya.

Kelahiran Muhammadiyah merupakan manifestasi dari ajaran Islam yang sesungguhnya, sehingga tidak mengherankan kalau organisasi tersebut mendapat sambutan yang hangat dari masyarakat Indonesia.Dalam waktu relatif singkat Muhammadiyah telah menyebar keseluruh pelosok Indonesia.Di Makassar Muhammadiyah dibawa oleh seorang pedagang batik keturunan Arab berasal dari Sumenep (Madura) yang bernama Mansyur Yamani sekitar tahun 1922.Mansyur Yamani merupakan anggota perserikatan Muhammadiyah cabang Surabaya, yang waktu itu dipimpin oleh K.H. Mas Mansyur.

Di daerah Makassar Mansyur Yamani berkenalan dengan para pemuka-pemuka agama yang tergabung dalam As-Shiratal Mustaqim yang juga merupakan relasi berdagangnya. Setelah kurang lebih 3 tahun berdiskusi dan saling bertukar pikiran dengan relasinya itu akhirnya mereka sepakat untuk mendirikan Muhammdiyah, pada tanggal 30 Maret 1926 berdirilah Muhammadiyah Group Makassar dengan pengurus pertamanya $\mathrm{H}$. Yusuf Daeng Mattiro sebagai ketua dibantu oleh beberapa pengurus lainnya seperti $\mathrm{H}$. Abdullah, Mansur Yamani, H. Ahmad Daeng Gambang, Muh. Yahya, H. Ahmad Daeng Minggu dan Abdul Karim dan ditambah dengan sembilan orang anggota lainnya (Radjab, 1999: 10).

Sekitar akhir tahun 1926, Muhammadiyah Group Makassar ditingkatkan menjadi Muhammadiyah Cabang Makassar dengan K.H. Abdullah sebagai ketuanya didampingi oleh tokoh-tokoh lainnya yang juga menjadi pengurus sejak mula didirikannya antara lain H. Nuruddin Daeng Magassing sebagai sekretatis. Sejak disepakati menjadi ketua Muhammadiyah cabang Makassar, K.H. Abdullah mencurahkan seluruh waktu dan perhatiannya mengembangkan dan mengajarkan cita-cita Muhammadiyah.

Dalam perkembangannya sebagai organisasi dakwah dan sosial, Muhammadiyah Makassar berkembang dengan pesat meskipun mengalami banyak hambatan pada awal berdirinya. Perkembangan ini didukung kerena kesadaran dari ajaran untuk pemurniaan agama Islam itu sendiri sehingga kader-kadernya bersemangat untuk menyebarluaskanya keseluruh daerah Sulawesi Selatan dan Makassar secara khusus dimana mereka melihat banyak terjadi penyimpangan itu.. Meskipun begitu Muhammadiyah tak jarang berselisih dengan masyarakat setempat, terutama benturan dengan pemuka adat terkait persoalan adat kebiasaan yang dilaksanakan oleh para penduduk yang sudah mengakar jauh sebelum Muhammadiyah masuk di Makassar yang dianggap sebagai penyimpangan agama oleh Muhammadiyah. Usaha Muhammadiyah sebagai gerakan agama dan sosial sudah banyak dilihat hasilnya sampai sekarang, misalnya pembangunan masjid di kampung-kampung dan berdirinya lembaga pendidikan Muhammadiyah dari tingkat TK sampai tingkat Universitas.

Secara etimologi, kata agama berasal dari bahasa Sansekerta, yaitu dari kata akar dan kata gam artinya pergi. Kemudian akar kata gam tersebut mendapat awalan a dan akhiran a, maka terbentuklah kata agama artinya jalan. Maksudnya, jalan untuk mencapai kebahagiaan. Selain itu, kata agama berasal dari bahasa Sansekerta yang akar katanya adalah a dan gama. A artinya tidak dan gama artinya kacau. Jadi, agama artinya tidak kacau atau teratur. Maksudnya, agama adalah peraturan yang dapat membebaskan manusia dari kekacauan yang dihadapi dalam hidupnya, bahkan menjelang matinya(Jalaluddin 2012:320).

De Groot mengemukakan bahwa religi sebagi jiwa yang disertakan Tuhan terikat kembali dengan-Nya, maksudnya bahwa manusia tidak bebas menurut kemauannya sendiri tetapi harus menuntut ketentuan hukum karena perlu adanya hukum yang mengikat. Ada tiga prinsip persamaan dalam memahami arti religi: pertama, kepercayaan terhadap tuhan dan hubungan manusia dengan-Nya yang dihayati sebagai Yang Maha Gaib. Kedua, hubungan 
antara manusia dengan Tuhan diwujudkan dalam bentuk kultus dan amalan-amalan yang bersifat ritual. Ketiga, bentuk kepercayaan dan cara berhubungan antara manusia dengan Tuhan diatur dalam bentuk doktrin dan ajaran tertentu (Sukardji 1993:27).

I. Menurut Winkler Prins dalam Algemene Encyclopaedie berasal dari bahasa Latin, yaitu dari kata religere atau religare yang berarti terikat, maka dimaksudkan bahwa setiap orang yang beragama adalah orang yang senantiasa merasa terikat dengan sesuatu yang dianggap suci. Kalau dikatakan berasal dari kata religere yang berarti berhati-hati, maka dimaksudkan bahwa orang yang ber-religi itu adalah orang yang senantiasa bersikap hati-hati dengan sesuatu yang dianggap suci.

II. Menurut Elisabeth K. Nottingham (1985:34) menyatakan bahwa agama bukan sesuatu yang dapat difahami melalui defenisi melainkan melalui deskripsi (penggambaran) dimana agama merupakan hal yang begitu sering "terdapat dimanamana" dan berkaitan dengan usaha-usaha manusia untuk mengukur dalamnya makna dari keberadaan diri sendiri dan alam semesta. Hal ini menggambarkan bahwa agama dapat membangkitkan kebahagiaan bathin dan juga perasaan takut dan ngeri. Dimana agama sebagai bentuk keyakinan manusia terhadap sesuatu yang bersifat supranatural yang seakan menyertai manusia dalam ruang lingkup yang luas.

III. Perlu dipahami dalam konsep agama ialah agama dalam kehidupan individu dan agama dalam kehidupan masyarakat. Agama dalam kehidupan individu berfungsi sebagai suatu sistem nilai yang memuat norma-norma tertentu yang menjadi kerangka acuan dalam bersikap dan bertingkah laku. Sedangkan agama dalam kehidupan masyarakat bahwa menganggap masyarakat itu gabungan dari kelompok individu yang terbentuk berdasarkan tatanan sosial tertentu (Jalaluddin 2012:320).

IV. Agama dan religi ialah suatu kepercayaan atas adanya yang agung di luar manusia, dan suatu tata penyembahan kepada yang agung tersebut, serta suatu kaidah yang mengatur hubungan manusia dengan yang agung, hubungan manusia dengan manusia dan hubungan manusia dengan alam yang lain, sesuai dengan tata kepercayaan dan tata penyembahan tersebut.

V. Pengertian agama sebagai kesatuan sistem kepercayaan merupakan praktek dimana suatu masyarakat atau kelompok berjagajaga menghadapi persoalan terakhir. Bahkan lebih jauh dikatakan bahwa agama merupakan seperangkat jawaban koheren atas dilema keberadaan manusia sehingga menjadikan kehidupan lebih bermakna (Yusuf, 2001:53).

VI. Senada dengan pendekatan Talcoot Parsons yang mengatakan :"A religion we will be define as a set beliefs, practices and institution wich man have avAlved in various societies" (Kipp and Rodgers, ed., 1982:174-175). Hal tersebut mengandung makna bahwa agama merupakan seperangkat kepercayaan dan kebiasaankebiasaan serta lembaga-lembaga yang dapat ditemukan dalam berbagai kelompok masyarakat.

VII. Berdasarkan pengertian tersebut, maka pada agama dan religi terdapat empat unsur penting, yaitu: 1) pengakuan atau kepercayaan terhadap adanya yang agung, 2) hubungan atau penyembahan terhadap yang Agung itu dalam bentuk ritus, kultus dan pemujaan, 3) kaidah/doktrin, sehingga muncul balasan berupa kebahagiaan bagi yang berbuat baik/jujur, dan kesengsaraan bagi yang berbuat buruk/jahat, 4) tata sikap terhadap dunia, yang menghadapi dunia ini kadang-kadang sangat terpengaruh sebagaimana golongan materialisme atau menyingkir/menjauhi/uzlah dari dunia, sebagaimana golongan spritualisme. Selanjutnya, kata din secara etimologi berasal dari bahasa Arab, artinya: patuh dan taat, undang-undang, peraturan dan hari kemudian. Maksudnya, orang yang berdin ialah orang yang patuh dan taat terhadap peraturan dan undang-undang Allah untuk mendapatkan kebahagiaan di hari kemudian(Yusuf, 2001:56).

VIII. Sedangkan menurut terminologi, din adalah peraturan Tuhan yang membimbing manusia yang berakal dengan kehendaknya sendiri untuk kebahagiaan dan kesejahteraan di dunia dan di akhirat. Berdasarkan pengertian din tersebut, maka din itu memiliki empat ciri, yaitu: 1) din adalah peraturan Tuhan. 2) din hanya diperuntukkan bagi manusia yang berakal, sesuai hadis Nabi yang berbunyi: Al-din 
huwa Al-aqlu la dina liman la aqla lahu, artinya: agama ialahakal tidak ada agama bagi orang yang tidak berakal. 3) din harus dipeluk atas dasar kehendak sendiri, firman Allah: la ikraha fi Al-din, artinya: tidak ada paksaaan untuk memeluk din (agama). 4) din bertujuan rangkap, yakni kebahagiaan dan kesejahteraan dunia akhirat.

Agama dan sistem kepercayaan sudah menjadi bagian yang tidak terpisahkan dalam kehidupan manusia. Sistem kepercayaan dalam bentuk animisme dan dinamisme berkembang seiring dengan munculnya kepercayaan akan adanya kekuatan lain di luar kekuatan manusia. Nottingham, mendefenisikan agama dengan melihat manusia sebagai pelaku, dan mereka memberi tekanan khusus pada bagaimana menggunakan agama dalam kehidupan sosialnya, dan bahkan dalam semua segi kehidupannya (Nottingham, 2002: 6).

\section{METODE}

Penelitian ini adalah penelitian sejarah yang bersifat deskriptif analitik dengan tujuan untukmenemukan dan mendeskripsikansecara analisis serta menginterpretasikan kondisi sosio kultural munculnya organisasi Muhammadiyah sampai pada respon masyarakat terhadap organisasi Muhammdiyah dalam mengelola pendidikan di Kota Makassar.

Jenis penelitian ini adalah penelitian dengan menggunakan pendekatan deskriptif analitis. Teknik penulisan dan pengumpulan data menggunakan metode sejarah dengan empat tahapan yakni heuristik (pengumpulan data), kritik (analisa data), interpretasi (menafsirkan data), historigrafi (menuliskan data menjadi suatu peristiwa yang utuh).

\section{HASIL DAN PEMBAHASAN}

\section{a. Masuknya Muhammadiyah di Kota Makassar}

Sulawesi menjadi salah satu daerah yang mendapat pengaruh dari Muhammadiyah terbukti dengan berdirinya Muhammadiyah Cabang Makassar pada tahun 1926 sebagai cabang Muhammadiyah pertama di luar pulau Jawa dan Sumatra (Darmawijaya; 2014: 467 ). Kehadiran Muhammadiyah di Makassar dimulai dari kedatangan Mansyur Al-Yamani di Makassar tahun 1924. Mansyur Al-Yamani dikenal sebagai seorang pedagang batik dari Surabaya, yang membuka toko di Passar Straat (sekarang jalan Nusantara) Makassar (Abdul Wahab dalam Darmawijaya, 2014; 472).

Walaupun organisasi Muhammadiyah ini agak terlambat masuk ke wilayahSulawesi Selatan tepatnya di Makassar yakni pada tahun 1926, namun Muhammadiyahmampu menarik perhatian kaum Pedagang, kaum Ulama, dan kaum Bangsawan.Bahkan Muhammadiyah mampu menarik sebagian orang keturunan Arab untukmenjadi kadernya. Di tangan mereka, Muhammadiyah yang pada awalnya hanya adadi Makassar, namun kemudian mampu berkembang ke berbagai kota di pedalamanSulawesi Selatan.

Anggota Muhammadiyah cabang
Makassar sampai beberapa tahun sesudahterbentuknya, tersebar ke beberapa kampung dalam kota Makassar, bahkan juga adayang berdomisili di luar kota di pedalaman Sulawesi Selatan. H. A. S. Daeng Muntu,konsul Muhammadiyah Sulawesi Selatan yang kedua menyatakan dalam bukunya(Langkah dan usaha kerja) bahwa setelah keluarnya anggota Shiratal Mustaqiem dariMuhammadiyah, maka hanya tersisa 17 orang anggota Muhammadiyah cabangMakassar. Masing-masing anggota tersebut menjadi kader dalam mengembangkanpaham dan organisasi Muhammadiyah di tempatnya masing-masing, terutamadikalangan keluarga dan sahabat karibnya. Berkat usaha para kader Muhammadiyahitu, pada tahun 1928 telah terbentuk 4 (empat) grup Muhammadiyah di dalam kotaMakassar, yaitu:

a. Muhammadiyah grup kampung Bontoala, dipimpin oleh Sulaiman DaengMatutu.

b. Muhammadiyah grup kampung Pisang, grup ini banyak beranggotakan orangSelayar dipelopori oleh Daeng Mammudji, Sabang Daeng Ngago dan Bahar.

c. Muhammadiyah grup Mariso di bagian selatan kota Makassar sekitar jalanRajawali, pelopor dan pimpinannya adalah Haji Tuppu Daeng Palallo seorangpegawai KPM (Perusahaan pelayaran zaman kolonial Belanda), didampingioleh Madenum Daeng Sutte dan Abdul Haji Daeng Mangka.

d. Muhammadiyah grup Lariangbangi di lingkungan distrik Makassar di bagiantimur kota Makassar, sebelah timur jalan Veteran. Penggerak Muhammadiyahdi grup ini kebanyakan dari Selayar dengan Daeng Masino sebagaipimpinannya. 
Keempat grup Muhammadiyah tersebut di atas secara bergiliran mengadakantabligh (pengajian) di sekitar daerahnya masing-masing dengan mendatangkanpengurus pimpinan cabang Makassar.Selain dari usaha tabligh, masing-masing grupitu juga melakukan kegiatan di bidang penyantunan masyarakat yang dilaksanakanoleh urusan Penolong Kesengsaraan Oemoen (PKO).

Sejak resminya Muhammadiyah di Kota Makassar dari tahun 1926, Muhammadiyah banyak melakukan kegiatan atau aktifitas yang bermanfaat bagi masyarakat khususnya dalam bidang pendidikan. Usaha dan kegiatan Muhammadiyah dapat dikelompokkan ke dalam beberapa bidang, yakni: pertama, bidang keagamaan, yang meliputi memberikan tuntunan dan pedoman dalam bidang aqidah, ibadah, akhlak dan mu'amalah berdasarkan Al-Qur'an dan As-Sunnah, mendirikan masjid dan mushalla sebagai tempat sarana ibadah, mencetak kader ulama (fuqaha), menelaah berbagai kajian keislaman dan perkembangan umat Islam, memberi fatwa dan tuntunan dalam bidang Keagamaan dan melakukan dakwah. Kedua, bidang pendidikan, yang meliputi pendidikan yang beroerientasi kepada perpaduan antara sistem pendidikan umum dan sistem pesantren.

Adapun yang terpilih sebagai Bestuur Muhammadiyah grup Makassar periode pertama, ialah:

1. Haji Muhammad Yusuf Daeng Mattiro, sebagai Voorsitter (Ketua)

2. Haji Abdullah, sebagai Vice Voorsitter (Wakil ketua)

3. Muhammad Said Daeng Sikki, sebagai Secretaris (Sekretaris)

4. Haji Yahya, sebagai Penningmeester (Bendahara)

5. Mansyur Al-Yamani, sebagai Commissaris (Pembantu)

6. Muhammad Tahir Cambang, sebagai Commissaris (Pembantu)

7. Haji Ahmad, sebagai Commissaris (Pembantu)

8. Abdul Karim Daeng Tunru, sebagai Commissaris (Pembantu)

9. Haji Muhammad Yunus Saleh, sebagai Commissaris (Pembantu)

10. Daeng Minggu, sebagai Commissaris (Pembantu)

Dalam dunia pendidikan,

Muhammadiyah telah melakukan aktifitasnya dalam bentuk mendirikan madrasah-madrasah dan pesantren dengan memasukkan kurikulum pendidikan dan pengajaran ilmu pengetahuan umum dan modern (Mulkam, 2013:20) mendirikan sekolah-sekolah umum dengan memasukkan kurikulum keIslaman dan kemuhammadiyahan. Lembaga pendidikan yang didirikan kemudian dikelola dalam bentuk amal usaha dengan penyelenggaranya dibentuk sebuah majelis dengan nama Majelis Pendidikan Dasar dan Menengah, secara vertikal mulai dari Pimpinan Pusat sampai ke tingkat Pimpinan Cabang.

Konsep Islamberkemajuan pada Muhammadiyah dimasa K.H. Ahmad Dahlan merupakan penerjemahan Islam atau obyektivikasi ajaran Islamdalam bentuk gerakan pencerahan, pemajuan, serta percerdasan kehidupan umat Islam. Senada dengan penggambaran ini,Bahtiar (2011) menuliskan berikut:

"Pada diri K.H. Ahmad Dahlan, ideologi kemajuan itu menjadi modus penerjemahan nilai-nilai Islam atau obyektifikasi ajaran Islam kedalam bentuk agenda pencerahan, pemajuan, dan pencerdasan kehidupan umat serta kerjakerja kemanusiaan lainnya yang inklusif. Alam pikiran modern yang dibangun dalampersyarikatan dengan nilai-nilai prinsipil yang dipegang kukuh dalam prinsip menghasilkan tradisi tindakan dan etos kerja sebagai wujud riil dan amal saleh dari ajaran Islam. Risalah pergerakan Muhammadiyah sumbunya adalah ideologi kemajuan atau Islam yang berkemajuan".

Pendirian lembaga pendidikan oleh Muhammadiyah dilaksanakan sesuai dengan instruksi Majelis Dikdasmen yang diserahi tugas sebagai penyelenggara amal usaha di bidang pendidikan, dalam melaksanakan program mengacu kepada Tanfidz Keputusan Muktamar, Tanfidz Keputusan Musywil dan Tanfidz Keputusan Musda. Agar penyelenggaraan pendidikan di lingkungan Muhammadiyah mempunyai acuan dan aturan yang jelas, Majelis Dikdasmen Pimpinan Pusat Muhammadiyah telah mentanfidzkan Keputusan Rapat Kerja Nasional Majelis Pendidikan Dasar dan Menengah Muhammadiyah seluruh Indonesia.

Demikian pula sekolah dan masjid mengalami perkembangan yang sangat pesat. Segera setelah kongres, Muhammadiyah cabang Makassar membuka MadrasahMuallimin di Jalan Muhammadiyah. Untuk memanfaatkan semaksimal mungkin keberadaan Hamka di Makassar, dialah yang diangkat sebagai Kepala 
Sekolah. Setelahpembukaan Muallimin Muhammadiyah di Makassar, satu tahun kemudian Muhammadiyah cabang Majene juga membuka Madrasah Tsanawiyah. Berbarengan dengan itu, di beberapa daerah grup-grup baru juga dibuka yang kemudian disusul dengan pendirian amal-amal usaha. Selain itu digalakkan pula kegiatan dakwah amarma'ruf nahi munkar, baik berupa tabligh maupun debat dengan para ulama tradisionalyang menentang Muhammadiyah,

Sebagai bagian dari persyarikatan Muhammadiyah, Majelis Dikdasmen mempunyai tugas pokok adalah menyelenggarakan, membina, mengawasi dan mengembangkan penyelenggaraan amal usaha di bidang pendidikan dasar dan menengah. Dalam melaksanakan tugas pokok di atas, majelis pendidikan dasar dan menengah Muhammadiyah harus mengacu kepada visi, misi, asas dan tujuan pendidikan Muhammadiyah. Amal usaha pendidikan yang dikelola dan diselenggarakan oleh Majelis Dikdasmen tersebut adalah SD, MI, SMP, MTs, SMA, SMK, MA dan Pondok Pesantren (Sutrisno dkk, 2015).

Pentingnya pendidikan yang dilakukan oleh Muhammadiyah pertama, membangkitkan kesadaran nasional Indonesia melalui corak Islam.Kedua, melalui sekolah-sekolah Muhammadiyah, ideologi pembaharuan Islam tersebar luas, ketiga, meningkatkan penyebaran pengetahuan praktis pengetahuan yang modern.Ukuran nasionalisme agama Muhammadiyah terlihat dalam pemakaian bahasa Melayu atau yang kemudian dikenal sebagai bahasa Indonesia, sebagai bahasa organisasi.Bahasa Indonesia telah lama menjadi bahasa perantara dunia orang Islam Melayu, sebelum berkembangnya nasionalisme modern. Karena sebagai organisasi nasional, Muhammadiyah memakai bahasa Indonesia sebagai bahasa resmi kegiatan organisasi.

Secara umum fungsi dari pendidikan Muhammadiyah adalah: Pertama, meneruskan dan mewariskan nilai-nilai dan norma-norma tradisional yang sesuai dengan ajaran agama Islam. Kedua, mendorong pembaharuan sosial. Ketiga, mendorong inovasi bidang materi dan teknologi. Keempat, mewujudkan kebersamaan untuk mewujudkan integrasi dan pembangunan karakter kebangsaan.

Menurut pandangan sebagaian besar orang tua, bahwa mereka cenderung menyekolahkan anaknya ke Sekolah Muhammadiyah karena mereka memahami di Sekolah Muhammadiyah terjadi perpaduan mata pelajaran umum dengan mata pelajaran agama. Sehingga siswa-siswa disamping mendapatkan pelajaran juga mendapatkan pelajaran agama. Sebagaimana yang dituturkan oleh salah seorang orang tua siswa "saya menyekolahkan anakku di sekolah Muhammadiyah supaya mereka mendapat pengetahuan umum dan pemahaman atau pelajaran agama, karena penting juga mendapatkan pelajaran agama yang baik agar tahu masalah agama terutama agama Islam".

Dari pandangan orang tua siswa di atas, peneliti menyimpulkan, bahwa banyak orang tua siswa memasukkan anaknya ke sekolah Muhammadiyah baik di Sekolah Dasar, Sekolah Menengah Pertama, Sekolah Menengah Atas bahkan perguruan tinggi Muhammadiyah karena mereka menginginkan anaknya mendapatkan pengetahuan agama terutama agama Islam dan pengetahuan umum sebagai bekal anak mereka dalam kehidupan bermasyarakat.

Pada sekolah Muhammadiyah seirama dengan yang dikatakan oleh Triatmojo, bahwa dalam mengukur kemampuan siswa dan kebermanfaatan sebuah sekolah formal mengacu pada kemampuan keseimbangan yang dapat terlihat pada proses pendidikan yang melati akademis dan religiusita seperti kemampuan membaca, menghitung, menghafal, menganalisis dan memecahkan masalah dan berakhlak yang mulia. Murid juga dilatih akan kedisiplinan, tanggungjawab dan menjalin hubungan sosial dengan menepati jadwal sekolah, belajar mengerjakan tugas dan pekerjaan rumah, mengenakan pakaian seragam, bergaul dengan teman-teman sekolah, dan lain sebagaianya.

Selain dari berimbangnya materi yang diberikan di sekolah Muhammadiyah, para peserta didik dari berbagai sekolah menengah yang ada juga menyebutkan bahwa sekolah Muhammadiyah juga terlibat aktif dalam berbagai event dan kontes. Hal ini dibuktikan, bahwa disetiap sekolah Muhammadiyah selalu memiliki kegiatan ekstrakurikuler yang berorientasi untuk mengembangkan minat dan bakat siswa sehingga jika ada event maupun kontes yang diselenggrakan. Sekolah-sekolah Muhammadiyah tentunya tidak mau kalah dari sekolah-sekolah lainnya sehingga akan selalu ambil bagian dalam kegiatan tersebut.

\section{SIMPULAN DAN SARAN}


Kehadiran Muhammadiyah di Makassar dimulai dari kedatangan Mansyur Al-Yamani di Makassar tahun 1924.Al-Yamani dikenal sebagai seorang pedagang batik dari Surabaya, yang membuka toko di Passar Straat sekarang jalan Nusantara Makassar. Dalam perkembangannya Muhammadiyah kemudian membentuk cabang di di Kota Makassar misalnya Makassar, Bontoala, Pisang, Mamajang, Mariso Laribangi, Jongayya, BaraBarayya, Mimbar, Ujung Tana', Tallo, LayingParalayang, Karunrung, Tallo Baru, Panakkukang, Sambung Jawa, Maccini, Manggala, Biring Kanaya dan Minasaupa. Dalam dunia pendidikan, Muhammadiyah telah melakukan aktifitasnya dalam bentuk mendirikan madrasah-madrasah dan pesantren dengan memasukkan kurikulum pendidikan dan pengajaran ilmu pengetahuan umum dan modern.Semenjak berdiri pertama kali Muhammadiyah menitikberatkan kegiatannya di bidangpendidikan, disamping da'wah dan sosial, dibidang pendidikan Muhammadiyah meletakkan pada dasar Islam, berpedoman pada Al Qur'an dan Hadits.Dengandasar tersebut Muhammadiyah Kota Makassar mendapat respon yang positif terhadap masyarakat Kota Makassar. Hal ini tidak terlepas dari peran Muhammadiyah Kota Makassar untuk membentuk manusia muslim yangberakhlak mulia, cakap, percaya pada diri sendiri, dan berguna bagimasyarakat, Pendidikan Islam bersifat pribadi dan masyarakat.

Saran dari penelitn ini adalah (1) Dapat dijadikan rujukan atau referensi untuk melakukan penelitian selanjutnya tentang Muhammadiyah secara umum dan khususnya Muhammadiyah di Kota Makassar . (2) Dapat menjadi masukan terhadap organisasi Muhammadiyah dalam meningkatkan kualitas pendidikan pada sekolah-sekolah binaan Muhammadiyah. (3) Hasil penelitian tentang Muhammadiyah di Makassar diharapkan untuk dipelajari dan diketahui oleh masyarakat dan generasi muda agar memahami tentang Mumammadiyah Kota Makassar.

\section{DAFTAR RUJUKAN}

Anshoriy, Nasruddin. 2010, Matahari Pembaharuan. Jogjakarta:Bangkit Publisher.
Al Asy'ari, Deni, dkk. 2005. Pemberontakan Kaum Muda Muhammadiyah. Yogyakarta:Resist Book.

Bosra, Mustari. 2008. Tuan Guru, Anrong Guru dane Guru. Makassar: La GAligo Press.

Bosra, Mustari dkk. 2005. Menapak Jejak: Sejarah gerakan dan biografi ketuaketua

Muhammadiyah Sulawesi Selatan. Yogyakarta: Suara Muhammadiyah.

Darmawijaya. 2014. Sejarah Muhammadiyah Di Sulawesi Selatan 1926-1942. JurnAl lektur keagamaan, vol 12. No 2

HambAli, Hamdan. 2006. Ideologi dan Strategi Muhammadiyah. Yogyakarta: Suara Muhammadiyah.

Hariyono. 1995. Mempelajari Sejarah Secara Efektif. Jakarta: Pustaka Jaya.

Ibrahim, Absari dkk. 2015. "Pengaertian, Fungsi dan Peran Kurikulum" Universitas Khaerun Ternate.

Jalaluddin Fahmi, Hamid Ilham dkk. 2015. Matahari pembaharuan di SERAMBI MADINAH menelusuri tapak sejarah Muhammadiyah kota Makassar. Makassar: Majelis Pustaka PDM Kota Makassar \& LSQ Makassar.

Jurdi, Syarifuddin. 2010. Muhammadiyah dalam Dinamika Politik Indonesia 1966-2006. Yogyakarta: Pustaka Pelajar

Kartodirjo, Sartono. 1993. Pendekatan Ilmu Sosial Dalam Metodologi Sejarah. Jakarta: Gramedia Pustaka Utama.

Mappangara, Supriadi dan Irwan Abbas. 2003. Sejarah Islam di Sulawesi Selatan. Makassar: Lamacca Press.

Mulksan, Munir. 2007. Pesan dan Kisah K. H. Ahmad Dahlan Dalam Hikmad

Muhammadiyah. Yogyakarta: Suara Muhammadiyah.

Majelis Pustaka dan Informasi Pimpinan Pusat Muhammdiyah. 2013. 100 Tahun Muhammadiyah Menyinari Negeri. Yogyakarta: Majelis Pustaka dan Informasi Pimpinan Pusat Muhammdiyah.

Mulkam, Abdul M. 2013. Marhaenis Muhammadiyah: Ajaran dan Pemikiran K.H. Ahmad Dahlan. Yogyakarta: GAlang Pustaka

Musfirah;2014:Sejarah Muhammadiyah di Sulawesi selatan, musfirah9.blogspot.co.id. diakses 19 Desember 2017

Munir Mulkan, Abdul. 2013. Marhaenis Muhammadiyah, Ajaran dan Pemikiran 
K.H. Ahmad Dahlan. Yogyakarta: GAlang Pustaka

Pasha, Mustafa kamal dan Ahmad Adaby Darban.2005. Muhammadiyah Sebagai Gerakan Islam.Yogyakarta: Citra Karsa Mandiri.

Radjab, Wahab. 1999. Lintasan Perkembangan dan Sumbangan Muhammadiyah di Sulawesi Selatan. Jakarta: IPPSDM-WIN

Surat kabar Pedoman Karya. 2015. Muktamar Muhammadiyah Dari Makassar ke Makassar.
Sukardji, K.1993. Agama-Agama yang Berkembang di Dunia dan Pemeluknya. Bandung:Angkasa.

Suparman. 1993. Muhammadiyah dan Peranannya Dalam Menunjang Perkembangan Pendidikan Formal di Bima (1942-1990). Skripsi: Fakultas Ilmu sosial Universitas Negeri Makassar

Suwarno, Margono. 2005. Gerakan Islam Muhammadiyah. Yogyakarta: Persatuan Baru.

Yatim, Badri. 2006. Sejarah Peradaban Islam. Jakarta: Raja Grafindo. 